\title{
Resective Surgical Approach Shows a High Performance in the Management of Advanced Cases of Bisphosphonate-Related Osteonecrosis of the Jaws: A Retrospective Survey of 347 Cases
}

\author{
Filippo Graziani, DDS, PhD, * Paolo Vescovi, DDS, $†$ \\ Giuseppina Campisi, DDS, $\neq$ Gianfranco Favia, MD, DDS, $\mathfrak{d}$ \\ Mario Gabriele, MD, DDS, || Giovanni Maria Gaeta, DDS, 7 \\ Stefano Gennai, DDS, \#ranco Goia, DDS, ** Mario Miccoli, PhD, t† \\ Franco Peluso, MD, DDS, 执 Matteo Scoletta, DDS, $\int \mathbb{D}$ \\ Luigi Solazzo, MD, || || and Giuseppe Colella, MD, DDSף
}

Purpose: The aim of this study was to evaluate the results of the surgical treatment of bisphosphonaterelated osteonecrosis of the jaw (BRONJ) in a large cohort.

Materials and Methods: A retrospective cohort multicenter study was designed. Patients were enrolled if they were diagnosed with BRONJ and received operative treatment. Data on demographic, health status, perioperative, and surgical factors were collected retrospectively. The primary outcome variable was a change in BRONJ staging (improvement, worsening, or no change). Interventions were grouped by local debridement and resective surgery. Data were collected for other variables as cofactors. Univariate analysis and logistic regressions were then performed.

Results: Of the 347 BRONJ-affected subjects, 59\% showed improvement, 30\% showed no change, and $11 \%$ showed worsening. Improvement was observed in $49 \%$ of cases treated with local debridement and $68 \%$ of cases treated with resective surgery. Multivariate analysis indicated that maxillary location, resective surgery, and no additional corticosteroid treatment were associated with a positive outcome.

Conclusions: Surgical treatment of BRONJ appeared to be more effective when resective procedures were performed. Nonetheless, other factors, such as the absence of symptoms and the types of drug administration, should be taken into account before clinical decisions are made.

(c) 2012 American Association of Oral and Maxillofacial Surgeons

J Oral Maxillofac Surg 70:2501-2507, 2012

\footnotetext{
Received from the Department of Surgery, University of Pisa, Pisa, Italy.

*Assistant Clinical Professor, Section of Oral Surgery.

†Associate Professor, Department of Otolaryngologic/Dental/ Ophthalmological and Cervicofacial Sciences, University of Parma, Parma, Italy.

‡Associate Professor, Sector of Oral Medicine "V. Margiotta”, Department of Oral Sciences, University of Palermo, Palermo, Italy.

§Full Professor, Department of Odontostomatology and Surgery, University of Bari, Bari, Italy.

||Full Professor, Section of Oral Surgery.

I Contract Professor, Department of Odontostomatologic, Orthodontic and Surgical Disciplines, Second University of Naples, Naples, Italy.

\#Research Fellow, Section of Oral Surgery; PhD student, Department of Periodontology, University of Milano-Bicocca, Milan, Italy.

**Head Physician, Unit of Odontostomatology, Ospedale Mauriziano Umberto I, Turin, Italy.
}

††Research Fellow, Biostatistics Unit.

$\ddagger \ddagger$ Head Physician, Unit of Maxillofacial Surgery and Odontostomatology, San Sebastiano Hospital, Caserta, Italy.

\SConsultant, Oral Surgery Unit, Dentistry Section, Department of Clinical Physiopathology, University of Turin, Turin, Italy.

|| |Head Physician, Maxillofacial Surgery, ARNAS Ospedale Civico, Palermo, Italy.

ๆๆAssociate Professor, Department of Head and Neck Surgery, Second University of Naples, Naples, Italy.

Address correspondence and reprint requests to Dr Graziani: Department of Surgery, Section of Oral Surgery, University of Pisa, Via Roma, 67, 56126 Pisa, Italy; e-mail: filippo.graziani@med .unipi.it

(1) 2012 American Association of Oral and Maxillofacial Surgeons 0278-2391/12/701 1-0\$36.00/0

http://dx.doi.org/10.1016/i.joms.2012.05.019 
Bisphosphonates (BPs) are unstable equivalents of pyrophosphate that bind selectively to the bone and are supposed to act selectively on osteoclasts during high bone turnover, resulting in an antiresorptive effect. ${ }^{1,2}$ BPs are used widely in the management of systemic metabolic disorders, such as osteoporosis and Paget disease. ${ }^{3}$ Long-term BP endovenous infusion is administered to control hypercalcemia in malignant cases and to prevent skeletal complications, such as pathologic fractures or nerve compressions associated with bone metastasis, in different solid tumors, including breast, prostate, and lung cancers. ${ }^{4}$

However, BPs are strongly related to the development of a form of osteonecrosis of the jaws. ${ }^{5,6} \mathrm{BP}$ related osteonecrosis of the jaws (BRONJ) has been clearly defined as a clinical scenario characterized by 3 diagnostic features: 1) current or previous treatment with a $\mathrm{BP} ; 2$ ) the presence, for longer than 8 weeks, of exposed bone in the maxillofacial region; and 3) no history of radiation therapy to the jaws. ${ }^{7}$ Moreover, recent evidence has suggested that a nonexposed form of BRONJ may represent an insidious clinical variant that clinicians should always consider in their diagnostic process. ${ }^{8,9}$ The dental and medical communities are currently aware of this clinical entity. Clinical and research evidence is increasing, and several cases have been identified. ${ }^{6}$

BRONJ management is under debate within the medical and dental communities. Conservative approaches such as drug interventions, ${ }^{10}$ hyperbaric treatment, ${ }^{11}$ and laser applications ${ }^{12}$ have been advocated to decrease the symptoms and frequency of disease recurrence. In contrast, surgical management has been suggested to address necrotic bone exposures ${ }^{13,14}$ but appears to produce controversial clinical outcomes. Indeed, the results may be affected by numerous variables, such as current staging, the timing of the intervention, the technique used, the need for reconstruction, and the extent of the resection (ie, resective or local debridement). However, the data on the surgical management of BRONJ are very limited and usually associated with a single center.

Therefore, the purpose of this study was to collect and analyze the data from 9 clinical centers throughout Italy to describe and assess the outcomes of the surgical management of BRONJ. The investigators hypothesized that some factors, such as changes in clinical staging, may be associated with positive clinical outcomes. Among these, some characteristics of surgical intervention, such as bone removal, were observed. Therefore, the specific aims of the study were to describe the percentages of improvement in clinical staging according to the type of intervention (with or without bone removal) and the characteristics of the population.

\section{Materials and Methods}

\section{STUDY DESIGN AND SAMPLE}

To address the research hypothesis, the investigators designed a retrospective study involving 9 clinical centers throughout Italy: 6 in southern Italy; 1 in central Italy; and 2 in northern Italy. The centers in northern Italy included a broader network of 20 clinical departments, such as oral medicine; oral surgery; maxillofacial surgery; ear, nose, and throat; and hematology, and medical oncological units across the entire Piedmont region (Table 1). Because of the retrospective nature of this study, involving only routine procedures, IRB approval was not necessary.

Eligible subjects were identified from the patients of the respective clinical centers. The trial included only those 1) diagnosed with BRONJ, 2) surgically treated for BRONJ, 3) whose clinical files were available, and 4) treated from January 2004 through December 2008 with at least a 12-month follow-up.

\section{STUDY VARIABLES AND DATA COLLECTION}

Surgical outcome, the primary outcome, was assessed based on a 3-degree scale: improvement, no modification, or worsening. ${ }^{15}$ Improvement was defined as transition to a less severe stage, according to the classification of Ruggiero et al, ${ }^{16} 6$ months after the surgical intervention. The calibration of BRONJ was carried out by the researchers in 3 national BRONJ meetings. During data collection, disagreements were resolved after a discussion with the study coordinator (G.C.).

The descriptive analysis was performed based on the 3-degree scale. Inferential statistical analysis also was performed, with negative outcomes (no modification and worsening) grouped to increase the clinical relevance of the data.

Each outcome was then analyzed according to a set of predictor variables: demographic; health; perioperative; and operative.

Operative variables were grouped according to the types of surgical interventions and were divided into 2 procedural categories: local debridement and resection. Local debridement was comprised of all surgical interventions, such as sequestrectomy, soft tissue debridement, and curettage, that did not require bone surgery beyond the regular margins. Resective procedures were defined as corticotomy, surgical removal of the lesion, and extended bone removal without prejudice for the continuity of the mandible/maxilla. The choice of the type of intervention was based on the personal experience of the surgeon.

\section{DATA ANALYSES}

Data were entered into an Excel 2003 (Microsoft, Redmond, WA) database and proofread for entry er- 
Table 1. PREOPERATIVE CLINICAL VARIABLES VERSUS PRIMARY PREDICTOR VARIABLE

\begin{tabular}{|c|c|c|c|}
\hline Preoperative Clinical Variables & Local Debridement & Resective Intervention & $P$ Value \\
\hline \multicolumn{4}{|l|}{ Demographic variables } \\
\hline Men (\%) & $73(32 \%)$ & $36(30 \%)$ & .8 \\
\hline Age (yr) & $67.2 \pm 10.5$ & $65.6 \pm 11.7$ & .3 \\
\hline \multicolumn{4}{|l|}{ Clinical variables } \\
\hline Anatomic location & & & .006 \\
\hline Mandible & $154(68 \%)$ & $74(62 \%)$ & \\
\hline Maxilla & $59(26 \%)$ & $46(38 \%)$ & \\
\hline Mandible/maxilla & $14(6 \%)$ & $0(0 \%)$ & \\
\hline Dehiscence & $170(75 \%)$ & $116(97 \%)$ & .0001 \\
\hline Bone exposure & $163(72 \%)$ & $98(82 \%)$ & .1 \\
\hline Pus & $118(52 \%)$ & $89(74 \%)$ & .0006 \\
\hline Fistula & $41(18 \%)$ & $16(13 \%)$ & .4 \\
\hline Radiologic signs of necrosis & $102(45 \%)$ & $125(5 \%)$ & $<.0001$ \\
\hline Pain & $157(69 \%)$ & $92(77 \%)$ & .2 \\
\hline Absence of symptoms & $11(5 \%)$ & $18(15 \%)$ & .002 \\
\hline Stage & & & $<.0001$ \\
\hline I & $91(40 \%)$ & $17(14 \%)$ & \\
\hline II & $109(48 \%)$ & $94(78 \%)$ & \\
\hline III & $27(12 \%)$ & $10(8 \%)$ & \\
\hline Operator & & & $<.0001$ \\
\hline Maxillofacial surgeon & $107(47 \%)$ & $11(9 \%)$ & \\
\hline Oral-maxillofacial pathologist & $32(14 \%)$ & $2(2 \%)$ & \\
\hline DDS/DMD & $27(12 \%)$ & $1(1 \%)$ & \\
\hline Oral surgeon & $61(27 \%)$ & $106(88 \%)$ & \\
\hline Previous extraction & $148(65 \%)$ & $86(72 \%)$ & .2 \\
\hline \multicolumn{4}{|l|}{ Pharmacologic and medical variables } \\
\hline Bisphosphonate endovenous infusion & $213(94 \%)$ & $96(80 \%)$ & .002 \\
\hline Length of therapy (mo) & $24 \pm 20$ & $22 \pm 10$ & $<.0001$ \\
\hline Cortisone & $89(39 \%)$ & $28(23 \%)$ & .007 \\
\hline Chemotherapy & $173(76 \%)$ & $82(68 \%)$ & .2 \\
\hline Diabetes & $27(12 \%)$ & $6(5 \%)$ & .7 \\
\hline Other pathologies & $70(31 \%)$ & $29(24 \%)$ & .2 \\
\hline
\end{tabular}

Graziani et al. Surgical treatment of BRONJ. J Oral Maxillofac Surg 2012.

rors. The database was subsequently locked, imported into SPSS 17.0 for Windows (SPSS, Inc, Chicago, IL) and R 2.10 (Statistics Department of the University of Auckland, Auckland, New Zealand), formatted, and analyzed. The statistician was masked by the assignment of Greek letters to the variables. The Cramér-von-Mises and Shapiro-Wilk tests were used to check the normality of data distribution and assess whether parametric tests should be performed. The introductory phase was concluded with a statistical power analysis (retrospective) to estimate the sample size required for the specific tests. For significant variables, the $1-\beta$ value was mostly higher than 0.8 , ensuring a low risk of type II error in univariate analysis. Univariate analysis was performed by the $t$ test or the Mann-Whitney test, according to the normality of continuous data distribution, whereas the $\chi^{2}$ test with the Yates correction for continuity was used for the percentage data. Probabilities were determined with $95 \%$ confidence intervals. Logistic regressions were then applied in a generalized linear model used for binomial regression, with the outcome of sur- gical intervention as a dependent dichotomy variable (improved/not worse). The regression was performed according to the initial stage.

\section{Results}

\section{SAMPLE CHARACTERISTICS}

For the survey, 347 subjects (230 women, $66 \%$; average age, $67 \mathrm{yr}$; standard deviation, $11 \mathrm{yr}$; age range, 34 to $92 \mathrm{yr}$ ) were selected. An oncologic diagnosis had been made in most cases (90\%). Multiple myeloma was the primary pathology in $36 \%$ of cases (126 subjects), followed by breast cancer in 29\% (99 subjects), and prostate cancer in 10\% (34 subjects). Forty-three subjects received BPs for osteoporosis treatment (12\%). Other indications were chest, colon, and thyroid tumors. Thirty percent of the subjects also had concomitant pathologies. Nine percent of the subjects had diabetes, $20 \%$ had hypertension, and $7 \%$ had heart disease. BP administration was mainly endovenous (88\%). The BPs used were zoledronate 
(241 subjects, 60\%), followed by pamidronate (42 subjects, $10 \%$ ), alendronate (31 subjects, $8 \%$ ), clodronate (13 subjects, $3 \%$ ), and risedronate (3 subjects, $1 \%)$. Ibandronate and neridronate were taken by 2 separate subjects. The identification of BPs used was not possible in the remaining 15 subjects. The BP treatment was administered for an average of 23 months (range, 1 to $71 \mathrm{mo}$; $95 \%$ confidence interval, 20 to $24 \mathrm{mo}$ ) before the BRONJ diagnosis. One hundred fourteen subjects (33\%) also received corticosteroids.

The BRONJ lesions were mainly symptomatic (319 subjects, 92\%), and bone exposure was detectable in the vast majority of cases (305 subjects, $88 \%$ ). Pus was detected in $56 \%$ of cases (181 subjects) and fistulas in $17 \%$ (57 subjects). Sixty-five percent of the lesions were located in the mandible (226 subjects), 29\% (100 subjects) in the maxilla, and $6 \%$ in the maxilla and mandible. The main event leading to BRONJ was extraction (212 subjects, 63\%). A reasonable explanation for BRONJ was detected in $68 \%$ of cases $(226$ subjects). Prosthetic trauma was detected in 9 cases (3\%), and periodontal disease, osteitis, and other causes accounted for $1 \%$ ( 5 subjects) of the total. The most frequent stage of BRONJ was stage II (208 subjects, $60 \%$ ), whereas stage I (96 subjects, $28 \%$ ) and stage III (34 subjects, 10\%) were less common. The stages in the remaining $2 \%$ of the sample were not classified.

\section{CLINICAL DATA}

During follow-up, after the first 6 months, 51 subjects (15\%) died. Most treatments were performed by a dental graduate ( 242 cases, $70 \%$ ), whereas the remaining subjects were treated by a maxillofacial surgeon. The surgical interventions consisted mainly of local debridement (66\%).

For the surgical outcome, $59 \%$ of subjects showed improvement after surgery, 30\% showed no change, and $11 \%$ exhibited a worsening of their clinical condition. Univariate analysis of the factors affecting the outcome indicated that several preoperative clinical variables were associated with the clinical outcome (Table 1). The presence of preoperative clinical symptoms, such as pain, pus discharge, and fistulas, was associated with a negative prognosis. In particular, the location of the lesion (mandible), the administration of cortisone/endovenous BPs, and radiologic signs of necrosis were strongly associated with negative outcomes.

The characteristics of the 2 study populations (surgical debridement vs resective surgery) are presented in Table 2.

After surgical debridement, $49 \%$ of cases showed improvement, with no improvement in $35 \%$ and
Table 2. PROGNOSTIC VALUES OF PREOPERATIVE CLINICAL VARIABLES VERSUS PRIMARY OUTCOME

\begin{tabular}{|c|c|c|c|}
\hline $\begin{array}{c}\text { Preoperative Clinical } \\
\text { Variables }\end{array}$ & $\begin{array}{l}\text { Positive } \\
\text { Outcome }\end{array}$ & $\begin{array}{l}\text { Negative } \\
\text { Outcome }\end{array}$ & $\begin{array}{c}P \\
\text { Value }\end{array}$ \\
\hline \multicolumn{4}{|l|}{ Demographic variables } \\
\hline Age (yr) & $66.9 \pm 10.6$ & $67.5 \pm 11.2$ & .6 \\
\hline Men (\%) & $65(31 \%)$ & $46(33 \%)$ & .8 \\
\hline \multicolumn{4}{|l|}{ Clinical variables } \\
\hline Anatomic location & & & .0003 \\
\hline Mandible & $119(57 \%)$ & $109(79 \%)$ & \\
\hline Maxilla & $79(38 \%)$ & $23(17 \%)$ & \\
\hline Mandible/maxilla & $10(5 \%)$ & $6(4 \%)$ & \\
\hline Dehiscence & $194(93 \%)$ & $113(82 \%)$ & .04 \\
\hline Exposure & $153(73 \%)$ & $121(88 \%)$ & .004 \\
\hline Pus & $113(54 \%)$ & $90(65 \%)$ & .05 \\
\hline Fistula & $25(12 \%)$ & $29(21 \%)$ & .05 \\
\hline $\begin{array}{l}\text { Radiologic signs of } \\
\text { necrosis }\end{array}$ & $50(24 \%)$ & $73(53 \%)$ & $<.0001$ \\
\hline Pain & $146(70 \%)$ & $112(81 \%)$ & .04 \\
\hline Absence of symptoms & $17(8 \%)$ & $12(9 \%)$ & .9 \\
\hline Stage & & & .1 \\
\hline I & $65(31 \%)$ & $35(25 \%)$ & \\
\hline II & $127(61 \%)$ & $88(64 \%)$ & \\
\hline III & $17(8 \%)$ & $15(11 \%)$ & \\
\hline Operator & & & .07 \\
\hline $\begin{array}{l}\text { Maxillofacial } \\
\text { surgeon }\end{array}$ & $72(34 \%)$ & $65(47 \%)$ & \\
\hline $\begin{array}{l}\text { Oral-maxillofacial } \\
\text { pathologist }\end{array}$ & $15(7 \%)$ & $11(8 \%)$ & \\
\hline DDS/DMD & $15(7 \%)$ & $10(7 \%)$ & \\
\hline Oral surgeon & $108(52 \%)$ & $52(38 \%)$ & \\
\hline Previous extraction & $140(67 \%)$ & $97(70 \%)$ & .6 \\
\hline \multicolumn{4}{|l|}{$\begin{array}{l}\text { Pharmacologic and } \\
\text { medical variables }\end{array}$} \\
\hline $\begin{array}{l}\text { Bisphosphonate } \\
\text { endovenous } \\
\text { infusion }\end{array}$ & $178(85 \%)$ & $130(94 \%)$ & .003 \\
\hline $\begin{array}{l}\text { Length of therapy } \\
\text { (mo) }\end{array}$ & $25 \pm 19$ & $21 \pm 17$ & .07 \\
\hline Cortisone & $54(74 \%)$ & $61(56 \%)$ & .0006 \\
\hline Chemotherapy & $140(67 \%)$ & $108(78 \%)$ & .06 \\
\hline Diabetes & $15(7 \%)$ & $15(11 \%)$ & .4 \\
\hline Other pathologies & $61(29 \%)$ & $44(32 \%)$ & .6 \\
\hline
\end{tabular}

Graziani et al. Surgical treatment of BRONJ. J Oral Maxillofac Surg 2012.

worsening in the remaining $16 \%$. Resective surgery resulted in a statistically significant difference $(P=$ .002 ) because improvement was seen in $68 \%$, with no improvement in $27 \%$ and a worse clinical condition in $5 \%$.

Analysis showed positive outcomes (Table 3) in patients with stage II lesions treated with resective surgery. Conversely, patients with stage I lesions treated with local debridement showed greater, albeit modest, improvement. Those with stage III lesions showed no significant clinical improvement.

Logistic regression indicated that treatment, drug administration, and the location of the lesion could affect the outcome (Table 4). 
Table 3. PRIMARY PREDICTOR VARIABLE VERSUS PRIMARY OUTCOME

\begin{tabular}{lccc} 
& \multicolumn{2}{c}{ Outcome Variable } & \\
\cline { 2 - 3 } Predictor Variable & $\begin{array}{c}\text { Positive } \\
\text { Outcome }\end{array}$ & $\begin{array}{c}\text { Negative } \\
\text { Outcome }\end{array}$ & Total \\
\hline Local debridement & 122 & 105 & 227 \\
Resective surgery & 87 & 33 & 120 \\
Total & 209 & 138 & 347 \\
\hline
\end{tabular}

Note: A relative risk lower than 1 indicates a protective effect against a negative outcome, whereas a relative risk higher than 1 indicates a tendency toward a negative outcome. The relative risk for subjects who underwent resective surgery (reference group) is 0.7 (confidence interval, 0.4 to $0.8 ; P=.002$ ). Therefore, a resective intervention seems to have a significant protective effect against a negative outcome. The risk of subjects after a resective intervention to have a negative outcome is $30 \%$ lower than in subjects after local debridement.

Graziani et al. Surgical treatment of BRONJ. J Oral Maxillofac Surg 2012.

\section{Discussion}

This study retrospectively assessed, in a large cohort, the clinical results of different surgical interventions performed as part of the management of subjects affected by BRONJ. The rationale for the study was based on the hypothesis that some clinical factors may be prognostically associated with positive clinical outcomes. The primary focus was on the type of surgical intervention. Therefore, the specific aims of the study were to describe the percentage of improvement of clinical staging according to the type of intervention (with or without bone removal) and according to some characteristics of the population.
Numerous surgical interventions, ranging from conservative curettage of the necrotic lesion to major resection/reconstruction of the necrotic portion, have been advocated for the treatment of BRONJ. ${ }^{13,17,18}$ Usually, the decision to perform surgery reflects the attitude of the surgeon/school because there have been no randomized clinical trials evaluating the effectiveness of 1 specific technique over another. Moreover, the different ways in which the disease manifests may influence the decision as to whether to perform surgery. An analysis of the present data indicated that resective surgery can effect a clinical improvement because almost $70 \%$ of the patients showed disease regression. These results are significant because minor resective surgery has been used in more advanced cases (stages II and III), has limited morbidity, and may be performed with patients under only local anesthesia. The present data are in agreement with previous reports advocating resective surgery as an elective technique. ${ }^{19-21}$ Carlson et al. ${ }^{14}$ reported a success rate of $91 \%$ in 82 patients. These findings also are confirmed in 1 of the few prospective studies on BRONJ surgery, which showed that the minimal resection of necrotic bone and the closure of local soft tissue could be feasible treatment strategies to achieve clinical improvement 6 months after surgery. ${ }^{22}$

Conversely, conservative surgical treatment, namely the surgical removal/debridement of necrotic tissues, has yielded controversial results. Surprisingly, less severe cases, such as stage I, treated mainly with local debridement have not shown the same positive outcomes as noted in more advanced cases. Approximately half of those treated with local debridement do not show clinical improvement. Stanton and Bala$\operatorname{sanian}^{23}$ retrospectively analyzed 30 patients affected

\section{Table 4. MULTIVARIATE LOGISTIC REGRESSION OF FACTORS INFLUENCING A POSITIVE OUTCOME}

\begin{tabular}{llll} 
Factors Influencing Outcome & \multicolumn{1}{c}{ Reference Groups } & OR $(95 \% \mathrm{CI})$ & $P$ Value \\
\hline Age & 10 yr older & $1.1(0.9-1.04)$ & .4 \\
Gender & Male & $1.4(0.8-2.6)$ & .3 \\
Location & Maxilla & $0.4(0.2-0.7)$ & .009 \\
Pus & Absence & $0.6(0.3-1.1)$ & .1 \\
Pain & No pain & $0.6(0.3-1.2)$ & .2 \\
Corticosteroid & No corticosteroid treatment & $0.4(0.2-0.8)$ & .009 \\
Oral administration of BPs & BPs & $1(0.9-1.03)$ & .9 \\
Stage & 1 stage higher & $1.3(0.8-2)$ & .3 \\
Operator & DDS/DMD & $1.1(0.9-1.5)$ & .2 \\
Surgical intervention & Resective intervention & $0.3(0.2-0.7)$ & .004 \\
\hline
\end{tabular}

Note: An odds ratio lower than 1 indicates a protective effect against a negative outcome, whereas an odds ratio higher than 1 indicates a tendency to a negative outcome. Significant results were obtained for surgical intervention, corticosteroid treatment, and location. The probability of subjects not treated with corticosteroids to have a negative outcome is $60 \%$ lower than in the other patients. The same findings are noticed for lesions located in the maxilla. The probability to achieve a negative outcome after resective surgery is $70 \%$ lower than after local debridement.

Abbreviations: BPs, bisphosphonates; CI, confidence interval; OR, odds ratio. 
by BRONJ lesions treated with surgical debridement. Twenty-five patients showed a significant benefit, resulting in clinical success. However, no information on the stage of the disease before surgery and no follow-up on relapses were provided. Stockmann et $\mathrm{al}^{24}$ reported an $89 \%$ success rate 1 year after conservative surgery in 50 patients. Another report on 24 subjects treated with the removal of necrotic bone showed failure in only 4 subjects with stage III lesions. ${ }^{17}$ According to these investigators, conservative treatment may be a successful option for less advanced cases.

Some additional factors can affect outcome. From an epidemiologic point of view, lesions are more frequently associated with the mandible. ${ }^{23,25-27}$ This is probably due to the minor thickness of the mucosa and its lower vascularization compared with that of the maxilla. Indeed, an analysis of the present data indicated that maxillary lesions have a better prognosis. BRONJ is strongly associated with an oncologic diagnosis. These findings are compatible with those of previously reported studies. ${ }^{28,29}$ However, the positive association between the oral administration of BPs and a positive surgical outcome disagrees somewhat with previous reports based on smaller samples. ${ }^{17}$

Surgical outcome also appears to be influenced by corticosteroid therapy. Indeed, corticosteroids appear to be associated with more severe BRONJ lesions, with an unpredictable prognosis. ${ }^{30}$ Steroids are routinely incorporated into anticancer therapeutic regimens and may be administered intravenously or orally. Although steroid use has long been associated with osteonecrosis of the long bones, the role of corticosteroids in the pathogenesis of osteonecrosis is unclear. ${ }^{31,32}$ Therefore, a possible role of corticosteroid cessation during treatment needs further investigation.

The literature has reported various surgical options for the treatment of advanced BRONJ. However, the overall results can be affected by some possible biases. Most studies are retrospective. Moreover, the sample size is rarely comprised of more than 100 subjects, and short follow-ups are often reported. Therefore, the results may reflect the positive clinical scenario of a specific center more than the predictability of the technique. Also, 1 study did not take into account the levels of terminal C-telopeptide because most patients received treatment before C-telopeptide levels were found to be useful risk predictability markers. ${ }^{9}$ However, many studies have not confirmed the effectiveness of this test for patients with cancer or osteoporosis. ${ }^{33-36}$

The retrospective nature of the present study is counterbalanced by the larger sample of cases of surgical treatment of BRONJ than reported in the rest of the literature. However, further research based on prospective studies is needed to clarify these findings.

Surgical treatment options for BRONJ are still under debate, and no evidence-based guidelines are available. An analysis of the present data indicated that local debridement and resective surgery resulted in an improvement, albeit modest, in the overall clinical condition. Resective surgery appeared to be associated with a higher rate of clinical success compared with local debridement.

\section{Acknowledgments}

The kind assistance of the clinical and paramedical staffs of the units involved in the trial is gratefully acknowledged.

\section{References}

1. Bukowski JF, Dascher CC, Das H: Alternative bisphosphonate targets and mechanisms of action. Biochem Biophys Res Commun 328:746, 2005

2. Reszka AA, Rodan GA: Mechanism of action of bisphosphonates. Curr Osteoporos Rep 1:45, 2003

3. Fleisch HA: Bisphosphonates: Preclinical aspects and use in osteoporosis. Ann Med 29:55, 1997

4. Diel IJ, Solomayer EF, Bastert G: Bisphosphonates and the prevention of metastasis: First evidences from preclinical and clinical studies. Cancer 88:3080, 2000

5. Campisi G, Di Fede O, Musciotto A, et al: Bisphosphonaterelated osteonecrosis of the jaw (BRONJ): Run dental management designs and issues in diagnosis. Ann Oncol 18:vi168, 2007 (suppl 6)

6. Hewitt C, Farah CS: Bisphosphonate-related osteonecrosis of the jaws: A comprehensive review. J Oral Pathol Med 36:319, 2007

7. Advisory Task Force on Bisphosphonate-Related Osteonecrosis of the Jaws: American Association of Oral and Maxillofacial Surgeons position paper on bisphosphonate-related osteonecrosis of the jaws. J Maxillofac Surg 65:369, 2007

8. Fedele S, Porter SR, D'Aiuto F, et al: Nonexposed variant of bisphosphonate-associated osteonecrosis of the jaw: A case series. Am J Med 123:1060, 2010

9. Junquera L, Gallego L: Nonexposed bisphosphonate-related osteonecrosis of the jaws: Another clinical variant? J Oral Maxillofac Surg 66:1516, 2008

10. Marx RE, Cillo JE Jr, Ulloa JJ: Oral bisphosphonate-induced osteonecrosis: Risk factors, prediction of risk using serum CTX testing, prevention, and treatment. J Oral Maxillofac Surg 65: 2397, 2007

11. Freiberger JJ: Utility of hyperbaric oxygen in treatment of bisphosphonate-related osteonecrosis of the jaws. J Oral Maxillofac Surg 67:96, 2009

12. Vescovi P, Manfredi M, Merigo E, et al: Surgical approach with Er:YAG laser on osteonecrosis of the jaws (ONJ) in patients under bisphosphonate therapy (BPT). Lasers Med Sci 25:101, 2010

13. Williamson RA: Surgical management of bisphosphonate induced osteonecrosis of the jaws. Int J Oral Maxillofac Surg 39:251, 2010

14. Carlson ER, Basile JD: The role of surgical resection in the management of bisphosphonate-related osteonecrosis of the jaws. J Oral Maxillofac Surg 67:85, 2009

15. Vescovi $\mathrm{P}$, Merigo E, Meleti M, et al: Bisphosphonate-associated osteonecrosis $(\mathrm{BON})$ of the jaws: A possible treatment? J Oral Maxillofac Surg 64:1460, 2006

16. Ruggiero SL, Dodson TB, Assael LA, et al: American Association of Oral and Maxillofacial Surgeons position paper on bisphosphonate-related osteonecrosis of the jaws-2009 update. J Oral Maxillofac Surg 67:2, 2009

17. Wilde $\mathrm{F}$, Heufelder $\mathrm{M}$, Winter $\mathrm{K}$, et al: The role of surgical therapy in the management of intravenous bisphosphonates- 
related osteonecrosis of the jaw. Oral Surg Oral Med Oral Pathol Oral Radiol Endod 111:153, 2011

18. Scoletta M, Arduino PG, Dalmasso P, et al: Treatment outcomes in patients with bisphosphonate-related osteonecrosis of the jaws: A prospective study. Oral Surg Oral Med Oral Pathol Oral Radiol Endod 110:46, 2010

19. Abu-Id MH, Warnke PH, Gottschalk J, et al: "Bis-phossy jaws"High and low risk factors for bisphosphonate-induced osteonecrosis of the jaw. J Craniomaxillofac Surg 36:95, 2008

20. Marx RE, Sawatari Y, Fortin M, et al: Bisphosphonate-induced exposed bone (osteonecrosis/osteopetrosis) of the jaws: Risk factors, recognition, prevention, and treatment. J Oral Maxillofac Surg 63:1567, 2005

21. Ruggiero SL, Mehrotra B, Rosenberg TJ, et al: Osteonecrosis of the jaws associated with the use of bisphosphonates: A review of 63 cases. J Oral Maxillofac Surg 62:527, 2004

22. Bedogni A, Saia G, Bettini G, et al: Long-term outcomes of surgical resection of the jaws in cancer patients with bisphosphonate-related osteonecrosis. Oral Oncol 47:420, 2011

23. Stanton DC, Balasanian E: Outcome of surgical management of bisphosphonate-related osteonecrosis of the jaws: Review of 33 surgical cases. J Oral Maxillofac Surg 67:943, 2009

24. Stockmann P, Vairaktaris E, Wehrhan F, et al: Osteotomy and primary wound closure in bisphosphonate-associated osteonecrosis of the jaw: A prospective clinical study with 12 months follow-up. Support Care Cancer 18:449, 2010

25. Graziani F, Cei S, La Ferla F, et al: Association between osteonecrosis of the jaws and chronic high-dosage intravenous bisphosphonates therapy. J Craniofac Surg 17:876, 2006

26. Wutzl A, Biedermann E, Wanschitz F, et al: Treatment results of bisphosphonate-related osteonecrosis of the jaws. Head Neck 30:1224, 2008

27. Thumbigere-Math V, Sabino MC, Gopalakrishnan R, et al: Bisphosphonate-related osteonecrosis of the jaw: Clinical fea- tures, risk factors, management, and treatment outcomes of 26 patients. J Oral Maxillofac Surg 67:1904, 2009

28. Hoff AO, Toth B, Hu M, et al: Epidemiology and risk factors for osteonecrosis of the jaw in cancer patients. Ann N Y Acad Sci 1218:47, 2011

29. Otto S, Abu-Id MH, Fedele S, et al: Osteoporosis and bisphosphonates-related osteonecrosis of the jaw: Not just a sporadic coincidence-A multi-centre study. J Craniomaxillofac Surg $1: 45,2010$

30. Chiu CT, Chiang WF, Chuang CY, et al: Resolution of oral bisphosphonate and steroid-related osteonecrosis of the jaw-A serial case analysis. J Oral Maxillofac Surg 68:1055, 2010

31. Estilo CL, Van Poznak CH, Wiliams T, et al: Osteonecrosis of the maxilla and mandible in patients with advanced cancer treated with bisphosphonate therapy. Oncologist 13:911, 2008

32. Assouline-Dayan Y, Chang C, Greenspan A, et al: Pathogenesis and natural history of osteonecrosis. Semin Arthritis Rheum $32: 94,2002$

33. Bagan JV, Jiménez Y, Gómez D, et al: Collagen telopeptide (serum CTX) and its relationship with the size and number of lesions in osteonecrosis of the jaws in cancer patients on intravenous bisphosphonates. Oral Oncol 44:1088, 2008

34. Fleisher KE, Welch G, Kottal S, et al: Predicting risk for bisphosphonate-related osteonecrosis of the jaws: CTX versus radiographic markers. Oral Surg Oral Med Oral Pathol Oral Radiol Endod 110:509, 2010

35. Lazarovici TS, Mesilaty-Gross S, Vered I, et al: Serologic bone markers for predicting development of osteonecrosis of the jaw in patients receiving bisphosphonates. J Oral Maxillofac Surg 68:2241, 2010

36. Lehrer S, Montazem A, Ramanathan L, et al: Normal serum bone markers in bisphosphonate-induced osteonecrosis of the jaws. Oral Surg Oral Med Oral Pathol Oral Radiol Endod 106: 389, 2008 